\title{
New type of vulnerability curve gives insight in the hydraulic capacitance and conductivity of the xylem
}

Lidewei L Vergeynst, Jan Bogaerts, Annelies Baert, Lies Kips and Kathy Steppe

Laboratory of Plantecology, Faculty of Bioscience Engineering, Ghent University, Coupure links 653, 9000 Ghent

Belgium

Keywords: drought, vulnerability, cavitation, hydraulic capacitance, hydraulic conductivity, stem diameter variations, ultrasonic acoustic emissions (UAE)

\begin{abstract}
Drought vulnerability of trees and other woody plants is much debated in the context of climate change, which creates a high interest in understanding plant water relations. The role and functioning of internal water storage is crucial, but still insufficiently understood. Drought vulnerability is typically assessed by considering loss in conductivity in function of decreasing xylem water potential, in a so-called 'vulnerability curve'. The xylem water potential at which a certain percentage of conductivity is lost (usually $50 \%$ ) gives an indication of the vulnerability to cavitation. In a 'desorption curve', we can examine the release of water from internal storage tissues with decreasing water potential. Both curves are very valuable, but rely on a sequence of manual measurements (xylem water potential, hydraulic conductivity and water content) and are time-consuming. Therefore, we propose a new type of vulnerability curve that is based on continuous measurements of diameter shrinkage and ultrasonic acoustic emissions (UAE). We monitored weight loss, xylem diameter shrinkage and UAE and measured xylem water potential during the dehydration of excised branches of Vitis vinifera $L$. 'Johanniter'. The vulnerability curves could be interpreted in terms of water loss in elastic and inelastic tissues. The proposed method can be a tool to assess hydraulic capacitance and conductivity of the xylem.
\end{abstract}

\section{INTRODUCTION}

The internal storage of water makes trees, and other woody species, resilient to sudden fluctuations in soil water availability. In periods when canopy water loss cannot be supplied by root water uptake, depletion of internal water reserves can contribute to the transpiration stream and carbon uptake through the open stomata can be continued. The depletion of internal water reserves also buffers strong fluctuations in xylem water potential. Strong negative water potentials induce cavitation in xylem elements, which impairs the hydraulic conductivity of the stem. However, cavitation recovery is observed diurnally (Waring and Running, 1978; Tyree et al., 1986; Zufferey et al., 2011) as well as seasonally (Sperry et al., 1987; Perks et al., 2004), which means that a certain degree of cavitation can serve as water supply and can contribute to the hydraulic capacitance of the tree (Hölttä et al., 2009).

The hydraulic capacitance $\left(\mathrm{C}\left[\mathrm{kg} \mathrm{m}^{-3} \mathrm{MPa}^{-1}\right)\right.$ is the amount of water $\left[\mathrm{kg} \mathrm{m}^{-3}\right]$ released by the plant tissues for a unit drop in water potential ( $\psi[\mathrm{MPa}])$ (Meinzer et al., 2003) and can be calculated from a desorption curve. Depending on the dehydration stage, a different capacitance is observed in dehydrating wood segments (Tyree and Yang, 1990). Three distinct phases can be attributed to three main contributing tissues. 
The high $\mathrm{C}$ during the initial phase is attributed to 'capillary water', the release of water from embolized wood cells and intercellular spaces. The shrinkage of elastic tissues results in a second phase with lower $\mathrm{C}$ and when a certain $\psi$ threshold is reached, water release by cavitation allows again a higher $\mathrm{C}$ during the last dehydration stage. Only trees growing in very wet environments can benefit from the high $\mathrm{C}$ of 'capillary water'. Under temperate growing conditions, shrinkage of living cells in storage tissues is the main component of water storage. When drought events take place, cavitation might also deliver a contribution to the capacitive discharge of water. This contribution is often considered as negligible and more attention goes to the conductivity loss that is associated with cavitation. During the controlled or uncontrolled desiccation of a wood sample or whole plant, hydraulic conductivity is measured as the amount of water that can be forced through a sample when a pressure gradient is applied (Sperry et al., 1988). A vulnerability curve is constructed, which depicts increasing PLC (percentage of conductivity loss) versus decreasing $\psi[\mathrm{MPa}]$. The xylem water potential at which a certain PLC is reached (usually 50\%: $\Psi_{50}$ ) gives an indication of the vulnerability to cavitation (Choat et al., 2012).

Both the desorption curve and the vulnerability curve provide useful information on the water management and drought resistance of the considered (part of the) tree. Combining both curves gives a more comprehensive picture when studying the water relations. For example, the conductivity loss below a certain $\psi$, together with increased C, proves that cavitation is indeed responsible for the higher capacitance under conditions of low $\psi$ for stems of Thuja occidentalis, Tsuga canadensis and Acer saccharum (Tyree and Yang, 1990). In a study by Barnard et al. (2011), the $\psi_{50}$ of Pseudotsuga menziesii and Pinus ponderosa was paradoxically higher on the most arid site (east) of the Cascade Mountain Range. However, a higher hydraulic capacitance in the arid-site specimens was observed and probably contributed to a better resistance to drought.

The measurement of conductivity loss can be replaced by measuring ultrasonic acoustic emissions (UAE) (Lo Gullo and Salleo, 1993; Hacke et al., 2000; Rosner et al., 2006) to construct vulnerability curves. This procedure does not require manual conductivity measurements and is thus less time-consuming. In this line of thought, we want to go a step further and replace the water potential measurements by continuous monitoring of xylem diameter shrinkage. We propose an automatic method to obtain desorption-vulnerability curves in which the relationship between UAE and xylem diameter shrinkage gives information on both hydraulic conductivity and hydraulic capacitance of the xylem.

\section{MATERIALS AND METHODS}

The experiments were conducted with plant material from 1-year-old grapevines (Vitis vinifera L. 'Johanniter') that were grown outdoors in 50-L containers. The plants were abundantly watered and the leaves were packed in an envelop of plastic and aluminium foil the evening before we harvested the branches. Early in the morning, before sunrise, four branches of $60 \mathrm{~cm}$ length were cut under water and enclosed in a humid and light tight plastic bag for one hour, the ends covered with parafilm. These precautions were taken to bring the branch segments in a hydraulic equilibrium state. In the lab, the dehydration of the branches was monitored using a weighing scale (PS 4500/C/2, Henk Maas, Veen, Netherlands), three linear variable displacement transducers (LVDT, DF/5.0, Solartron Mobrey, Brussels, Belgium) and three ultrasonic acoustic emission (UAE) sensors (VS150-M sensor and ASCO-P signal conditioner, Vallen 
systeme, Icking, Germany). One branch segment was placed on the weighing scale without any sensor and stripped of all leaves. The other three branches were equipped with an UAE sensor in the middle of the segment using a clamp (as in Rosner et al. (2009)). Each second, the maximum signal amplitude (APK) was logged and only the values larger than $35 \mathrm{~dB}$ (background noise $+5 \mathrm{~dB}$ ) were retained. We installed an LVDT next to the UAE sensor on the xylem, where the bark was carefully removed and Vaseline was applied to prevent water loss through the bare xylem. Before and after the dehydration experiment, a wood sample of about $5 \mathrm{~cm}$ was taken from the end of each branch segment and oven dried until constant weight. With these samples, initial and final water content, and green and dry wood density, were calculated for each branch segment. The course of the water content of each branch segment was estimated by rescaling the continuous weight data to the range of water contents between initial and final water content in the samples. Volumetric water content (VWC) was calculated by multiplying mass fraction with initial dry wood density. During the first 36 hours, xylem water potential was determined each three hours on excised leaves of the three equipped branch segments using the pressure bomb (PMS Instrument Company, Corvalis, OR, USA).

\section{RESULTS AND DISCUSSION}

\section{Meaningful transition points in new desorption-vulnerability curve}

We displayed all measurements as a function of xylem diameter shrinkage (Fig. 1). The presented data are gathered during the first $84 \mathrm{~h}$ of dehydration. Two transition points characterize the dehydration process when considering the ensemble of xylem shrinkage, water loss and cumulative UAE.

The dehydration started with a continuous decrease in VWC with increased xylem shrinkage, which corresponded to water loss from elastic tissues. After an initial quiet period, cumulative UAE started to increase gradually. The slope change around $0.37 \mathrm{~mm}$ xylem shrinkage is the transition between a phase with little cavitation and a phase with sharply increasing cavitation, also observed by Tyree and Yang (1990). This is associated with an increase in water loss per unit decrease in xylem diameter. Up to the point of strong cavitation increase, xylem shrinkage was proportional to total water loss. Water loss by living cells in the xylem is related to xylem shrinkage in this phase, in the same way as water loss in the bark is proportional to bark shrinkage (Zweifel et al., 2001). In the second phase, reduced xylem shrinkage compared to the amount of water loss implies that more water is released by cavitation.

After the second transition point $(0.68 \mathrm{~mm}$ xylem shrinkage), UAE activity is lower. During cavitation, water in the lumen of xylem vessels is replaced by air. When all free water is replaced by air, the fibre saturation point (FSP) is reached. A further reduction in water content below FSP is associated with cell wall shrinkage (Roderick and Berry, 2000) and results in an abrupt change in physical properties of the wood (Roderick and Berry, 2000) with, for example, a strong increase in the velocity of ultrasonic acoustic waves (Sakai et al., 1990). This means that more and more noise from cracks, associated with strong deformation stresses that arise from cell wall shrinkage (Sakai et al., 1990; Wolkerstorfer et al., 2012), will reach the UAE sensor. Wolkerstorfer et al. (2012) could distinguish cracks from cavitation hits using the amplitude of the signal. Similarly, we also observed a decrease in 10-min average amplitude near the end of the cavitation phase (Fig. 2). During the final dehydration phase, the amplitude is variable and reaches also high values, probably due to the strong increase in wave 
velocity. The observations suggest that the second transition corresponds to the fibre saturation point. The volumetric water content at FSP $\left(80 \mathrm{~kg} \mathrm{~m}^{-3}\right)$, estimated with the formula of Roderick and Berry (2000), is indeed reached near the transition (Fig. 1).

$$
\alpha_{f}=0.2 \sqrt{\frac{\rho_{\text {water }}}{\rho_{b}}}
$$

In this formula (Roderick and Berry, 2000), $\alpha_{f}$ stands for mass fraction of water over oven-dry wood. The volumetric water content is obtained by multiplying $\alpha_{f}$ with the initial basic density of wood $\left(\rho_{b}=158.5 \mathrm{~kg} \mathrm{~m}^{-3}\right.$, mass of oven-dry wood divided by fresh volume). The calculated FSP is an integration over the whole segment, but is only gradually reached as the cavitation phase is completed. This explains why the maximum UAE amplitude and the observed transition occurs before FSP is reached.

\section{Diameter shrinkage on the $x$-axis}

In standard desorption and vulnerability curves, dehydration processes (water loss, cavitation or conductivity loss) are related to water potential. We chose to use xylem diameter on the $\mathrm{x}$-axis for two reasons. First, the water transport and storage model (Steppe et al., 2006; Steppe and Lemeur, 2007), developed at the Laboratory of Plant Ecology, UGent, Belgium, uses diameter variations as continuous output variable. Robust and reliable sensors are available to measure diameter variations continuously and across long periods in the field. It would, hence, be very useful if plant processes that occur during drought stress could be related to this easily available variable. Second, the automated and continuous measurements of diameter shrinkage greatly facilitate the procedure to obtain useful desorption or vulnerability curves. Transitions are also difficult to designate in a graph when only point measurements, each with a certain measurement error, are available.

During the first $36 \mathrm{~h}$ of the dehydration experiment, we could measure xylem water potential on detached leaves. Because the number of leaves per branch was limited and because measurements could only be conducted on non-wilted leaves, the range of $\psi$ measurements was restricted to the first phase and the beginning of the second phase. Here, xylem water potential decreased linearly with increasing xylem shrinkage ( $\psi=-0.8+3.7 \cdot$ XylemShrinkage, $\left.R^{2}=0.95\right)$. Outside this range, the linear relationship may not hold. Xylem diameter shrinkage was also used by Hölttä et al. (2005) to replace xylem potential in a field experiment. They plotted cumulative UAE versus maximum xylem shrinkage of Pinus sylvestris during two consecutive days and called it a "vulnerability curve".

\section{Hydraulic capacitance and conductivity of the xylem}

According to Zweifel et al. (2001), over-bark diameter shrinkage is proportional to water loss from the elastic tissues of the bark. We assume that xylem shrinkage is also proportional to water loss from elastic tissues (parenchyma) in the xylem up to the FSP. The cumulative UAE up to the FSP is likely to be proportional to the amount of water released by cavitation. If these assumptions are correct, the progress along the $\mathrm{x}-$ and $\mathrm{y}$ axis gives an idea of the relative contribution of the living and dead xylem tissue to the hydraulic capacitance of the xylem. Water loss from the water conducting xylem elements implies a reduction in hydraulic conductivity, so cumulative UAE is also a measure for reduction in hydraulic conductivity (Lo Gullo and Salleo, 1993; Hacke et al., 2000). 


\section{CONCLUSIONS}

We propose a new type of vulnerability curve measured by continuous plant sensors, which may help to assess the different components of the hydraulic capacitance (internal water reserves), and the vulnerability to cavitation in terms of hydraulic conductivity. We think that this automated and easy method can be valuable as screening procedure when we want to compare water relations in different environments, in different species and varieties, or throughout the same plant. Further experiments will be done to verify the validity of our new desorption-vulnerability method.

\section{ACKNOWLEDGEMENTS}

The authors thank the Fund for Scientific Research-Flanders (Belgium) for PhD funding granted to the first author.

\section{Literature Cited}

Barnard, D.M., Meinzer, F.C., Lachenbruch, B., McCulloh, K. A, Johnson, D.M. and Woodruff, D.R. 2011. Climate-related trends in sapwood biophysical properties in two conifers: avoidance of hydraulic dysfunction through coordinated adjustments in xylem efficiency, safety and capacitance. Plant Cell Environ. 34:643-654.

Choat, B., Jansen, S., Brodribb, T. J., Cochard, H., Delzon, S., Bhaskar, R., Bucci, S. J., Feild, T. S., Gleason, S. M., Hacke, U. G., Jacobsen, A. L., Lens, F., Maherali, H., Martinez-Vilalta, J., Mayr, S., Mencuccini, M., Mitchell, P. J., Nardini, A., Pittermann, J., Pratt, R. B., Sperry, J. S., Westoby, M., Wright, I. J. and Zanne, A. E. 2012. Global convergence in the vulnerability of forests to drought. Nature. 491:752-755.

Lo Gullo, M.A. and Salleo, S. 1993. Different vulnerabilities of Quercus ilex L. to freezeand summer drought-induced xylem embolism: an ecological interpretation. Plant Cell Environ 16:511-519.

Hacke, U.G., Sperry, J.S. and Pittermann, J. 2000. Drought experience and cavitation resistance in six shrubs from the Great Basin, Utah. Basic Appl. Ecol. 1:31-41.

Hölttä, T., Cochard, H., Nikinmaa, E. and Mencuccini, M. 2009. Capacitive effect of cavitation in xylem conduits: results from a dynamic model. Plant Cell Environ. 32:10-21.

Hölttä, T., Vesala, T., Nikinmaa, E., Perämäki, M., Siivola, E. and Mencuccini, M. 2005. Field measurements of ultrasonic acoustic emissions and stem diameter variations. New insight into the relationship between xylem tensions and embolism. Tree Physiol. 25:237-243.

Meinzer, F.C., James, S.A., Goldstein, G. and Woodruff, D. 2003. Whole-tree water transport scales with sapwood capacitance in tropical forest canopy trees. Plant Cell Environ. 26:1147-1155.

Perks, M.P., Irvine, J. and Grace, J. 2004. Xylem acoustic signals from mature Pinus sylvestris during an extended drought. Ann. For. Sci. 61:1-8.

Roderick, M.L. and Berry, S.L. 2000. Linking wood density with tree growth and environment :a theoretical analysis based on the motion of water. New Phytol. 149:473-485.

Rosner, S., Klein, A., Wimmer, R. and Karlsson, B. 2006. Extraction of features from ultrasound acoustic emissions: a tool to assess the hydraulic vulnerability of Norway spruce trunkwood? New phytol. 171:105-116. 
Rosner, S., Karlsson, B., Konnerth, J. and Hansmann, C. 2009. Shrinkage processes in standard-size Norway spruce wood specimens with different vulnerability to cavitation. Tree Physiol. 29:1419-1431.

Sakai, H., Minamisawa, A. and Takagi, K., 1990. Effect of moisture content on ultrasonic velocity and attenuation in woods. Ultrasonics 28:382-385.

Sperry, J.S., Donnelly, J.R. and Tyree, M.T., 1988. A method for measuring hydraulic conductivity and embolism in xylem. Plant Cell Environ. 11:35-40.

Sperry, J.S., Holbrook, N.M., Zimmermann, M.H., Tyree, M.T., 1987. Spring filling of xylem vessels in wild grapevine. Plant Physiol. 83:414-417.

Steppe, K., De Pauw, D.J.W., Lemeur, R. and Vanrolleghem, P.A. 2006. A mathematical model linking tree sap flow dynamics to daily stem diameter fluctuations and radial stem growth. Tree Physiol. 26:257-273.

Steppe, K. and Lemeur, R. 2007. Effects of ring-porous and diffuse-porous stem wood anatomy on the hydraulic parameters used in a water flow and storage model. Tree Physiol. 27:43-52.

Tyree, M.T., Fiscus, E.L., Wullschleger, S.D. and Dixon, M. A. 1986. Detection of xylem cavitation in corn under field conditions. Plant Physiol. 82:597-599.

Tyree, M.T., Yang, S., 1990. Water-storage capacity of Thuja, Tsuga and Acer stems measured by dehydration isotherms. The contribution of capillary water and cavitation. Planta 182:420-426.

Waring, R.H. and Running, S.W. 1978. Sapwood water storage: its contribution to transpiration and effect upon water conductance through the stems of old-growth Douglas-fir. Plant Cell Environ. 1:131-140.

Wolkerstorfer, S.V., Rosner, S. and Hietz, P. 2012. An improved method and data analysis for ultrasound acoustic emissions and xylem vulnerability in conifer wood. Physiol. Plant. 146:184-191

Zufferey, V., Cochard, H., Ameglio, T., Spring, J.-L. and Viret, O. 2011. Diurnal cycles of embolism formation and repair in petioles of grapevine (Vitis vinifera cv. Chasselas). J. Exp. Bot. 62:3885-3894.

Zweifel, R., Item, H. and Häsler, R. 2001. Link between diurnal stem radius changes and tree water relations. Tree Physiol. 21:869-77. 
Figures

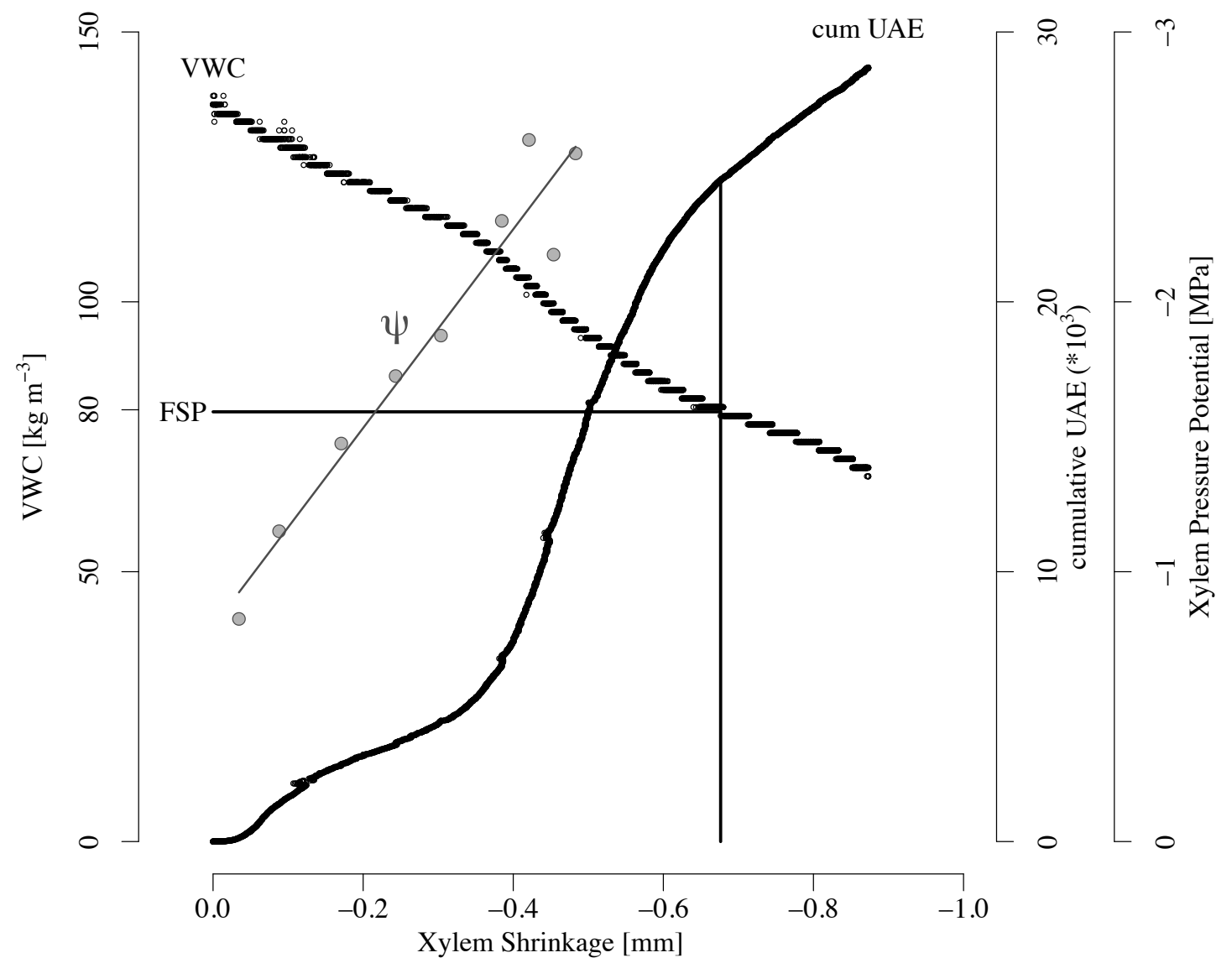

Fig. 1. Typical example of volumetric water content (VWC) and cumulative UAE showing three distinct phases in function of xylem shrinkage, separated by two clear transitions (at -0.37 and $-0.68 \mathrm{~mm}$ shrinkage). The second transition occurs when VWC reaches the fibre saturation point (FSP, $80 \mathrm{~kg} \mathrm{~m}^{-3}$ ). Xylem water potential $(\psi)$ decreases linearly with xylem shrinkage. 


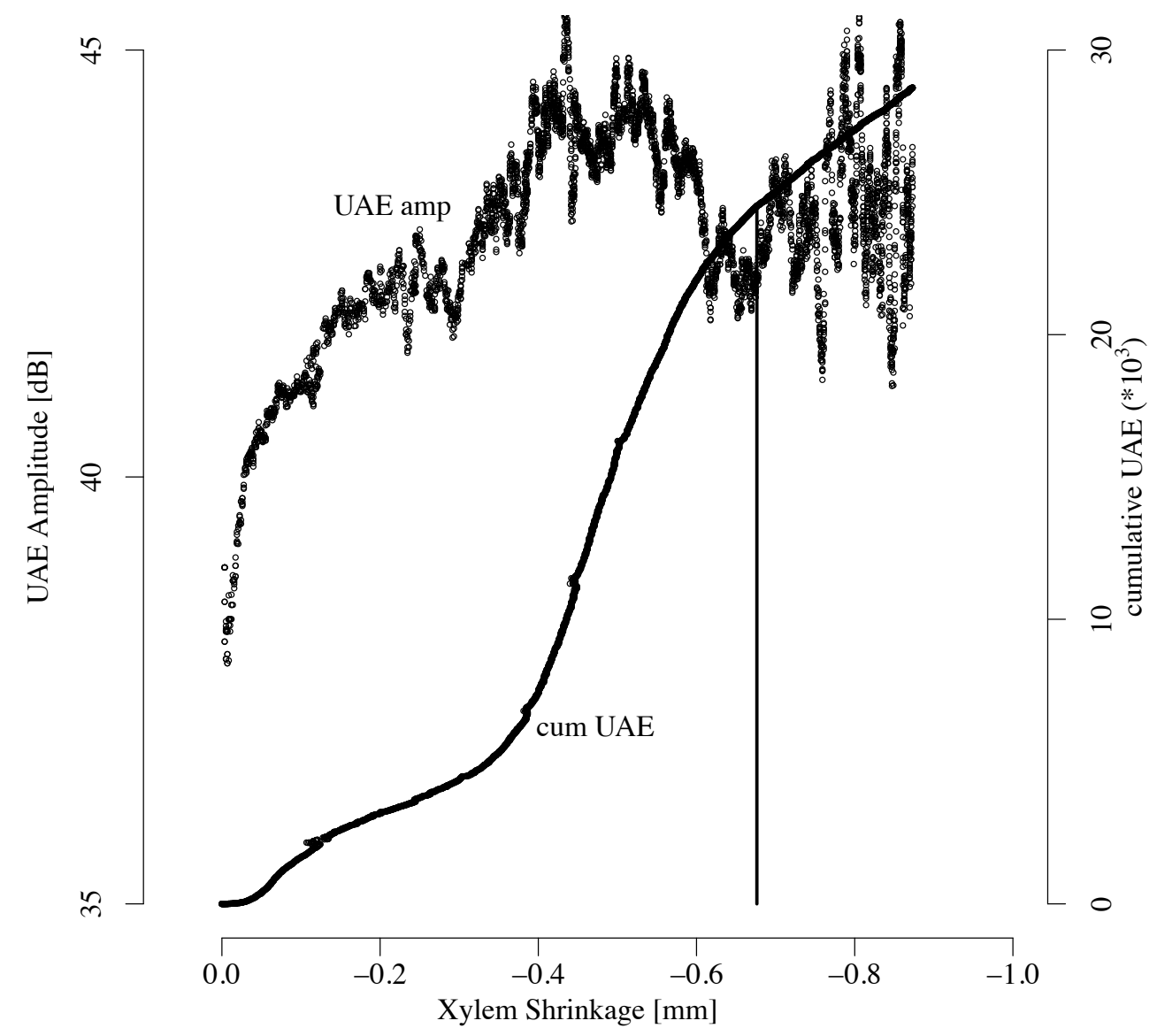

Fig. 2. Just before reaching the fibre saturation point (FSP) (vertical line), the UAE activity per unit of xylem shrinkage and the 10-min average amplitude of the acoustic signals decrease. In the last phase with less UAE detection, strong and less strong signals alternately show up. 